JIBS JOURNAL OF INTERNATIONAL

\title{
Building International Business Theory: A Grounded Theory Approach
}

\begin{tabular}{|r|l|}
\hline Journal: & Journal of International Business Studies \\
\hline Manuscript ID & JIBS-4547-2014-03-P.R4 \\
\hline Manuscript Type: & Perspective \\
\hline Keyword: & $\begin{array}{l}\text { International Business Theory < Topics, Grounded Theory, International } \\
\text { Business Theory Development }\end{array}$ \\
\hline \multicolumn{2}{|l}{} \\
\hline
\end{tabular}

\section{SCHOLARONE \\ Manuscripts}




\title{
Building International Business Theory: A Grounded Theory Approach
}

\author{
By \\ Dr. David M. Gligor \\ Assistant Professor of Marketing, \\ University of Mississippi, Department of Marketing, \\ University, MS, 38677, U.S.A. \\ Telephone: +1 (662) 915-2124 \\ Email: dgligor@bus.olemiss.edu \\ Dr. Carol Esmark \\ Assistant Professor of Marketing, \\ Mississippi State University, Department of Marketing, \\ Mississippi State, MS 39762, U.S.A. \\ Telephone: +1 (662) 325.3163 \\ Email: cesmark@bus.olemiss.edu \\ and \\ Dr. Ismail Gölgeci \\ Lecturer (Assistant Professor), \\ Norwich Business School, \\ University of East Anglia, Earlham Road, Norwich NR4 7TJ, United Kingdom \\ Telephone: +1603592310 \\ Email: I.Golgeci@uea.ac.uk
}

Corresponding author: Dr. David Gligor

Corresponding author's email: dgligor@bus.olemiss.edu

Ms. type: Perspective

Submitted: 17 March 2014

Revision 1: 13 September 2014

Revision 2: 17 February 2015

Revision 3: 5 June 2015

Revision 4: 4 September 2015

Accepted: 7 September 2015

Accepting editor:

Mary Zellmer-Bruhn, Area

Editor 


\title{
Building International Business Theory: A Grounded Theory Approach
}

\begin{abstract}
The field of international business (IB) is in need of more theory development (Morck \& Yeung, 2007). As such, the main focus of our manuscript was to provide guidance on how to build IB specific theory using grounded theory (GT). Moreover, we contribute to future theory development by identifying areas within IB where GT can be applied and the type of research issues that can be addressed using this methodology. Finally, we make a noteworthy contribution by discussing some of GT's caveats and limitations, particularly those relevant to IB. This effort is intended to spur further interest in the development of IB theory.
\end{abstract}

Keywords International Business Theory, Grounded Theory, International Business Theory Development 


\section{INTRODUCTION}

Theory building is necessary to advance the discipline of international business (IB) and empower its standing as a research field (Shenkar, 2004; Zahra, 2007). This is not an easy task as IB is truly multidisciplinary in scope and interdisciplinary in content (Birkinshaw, Brannen, \& Tung, 2011), which oftentimes entails the exploration of phenomena with complex and unclear behavioral dimensions. Indeed, it can be argued IB is a distinct research field with regard to context, depth, and phenomenon aspects from other business and management fields (Roth \& Kostova, 2003).

For example, the debate over the uniqueness of multinational corporations (MNCs) accentuates the need for IB theory development. Some organizational theorists would claim MNCs are not different from domestic companies but rather differ by degree only through the number of countries the MNCs operate in (Brannen, Piekkari, \& Tietze, 2014). However, some IB scholars claim MNCs are different from domestic companies by both degree and kind and constitute completely distinct entities (Nachum \& Keeble, 2001). If MNCs are only different by degree, then the IB research theory building efforts could be reduced to delineating the range of variation within which a theory is robust (Westney, 1993). However, if MNCs are actually different kinds of organizations with specific features that make existing theories and paradigms inapplicable, then IB research has the opportunity to significantly extend current theories and generate new ones (Westney, 1993). For example, Roth and Kostava (2003) point out language as a variable making MNCs distinct by kind and opening up opportunity for novel theory development.

IB's multidisciplinarity, interdisciplinarity, and distinctiveness impose a myriad of challenges for theory building that could be met with exploratory research. This research approach can help further understand the processes and mechanisms involved in IB research 
(Yeung, 1995) and build theory (Burgelman, 2011; Colquitt \& Zapata-Phelan, 2007).

Exploratory research leads to novel research questions and helps ask the right questions, which constitute a keystone of theory building (Buckley, 2002). Nevertheless, the lack of theory development in IB (Shenkar, 2004) has made it difficult to define and sustain the identity and research agenda of the field (Buckley, 2002). This shortcoming makes it oftentimes a mere application of broader disciplinary research with international flavor (Doz, 2011) lacking clear-cut, big research questions (Buckley, 2002).

As a distinctive and broadly applicable methodology for exploratory and inductive research (Corley, 2015; O’Reilly, Paper, \& Marx, 2012), grounded theory (GT) can help overcome some of the theoretical challenges IB faces. GT is particularly useful in studying behavior and change (Corley, 2015; Goulding, 1998), understanding problematic, intricate, and little known social phenomena, and being flexible to allow theory to emerge from data (Mello \& Flint, 2009). Importantly, both qualitative and quantitative data can be successfully used within GT. It is a context-rich methodology truly sensitive to real life problems, unlike commonplace variable-focused analysis (Glaser \& Strauss, 1967). GT allows building accurate, insightful, useful, and relevant theory, as it helps researchers come "skin close to the lived experience and incidents of the management world and make sense of them" (Fendt \& Sachs, 2008, p. 448) and engage "a phenomenon from the perspective of those living it" (Corley, 2015, p. 1). Such theoretical advancements in the IB field could enable genuine and thorough comprehension of diverse, dynamic, and multifaceted IB phenomena and ultimately facilitate the development of means for controlling such phenomena in a world experiencing unprecedented levels of internationalization of business. Thus, GT is often superior to relying solely on deductive reasoning and/or intellectual craftsmanship (O'Reilly et al., 2012) for theory building and elaboration. 
The depth, phenomenon, and context are vital aspects that differentiate IB from the settings where many of the theories applied were formulated. GT "is most suited toward inductive examinations seeking deep insights into a phenomenon and its connections with the context" (Corley, 2015, p. 1). Moreover, GT stands out in building and elaborating theory by bringing rigor and acumen into research through firsthand and in-depth exploration, because "the constant overlap and interplay between data collection and analysis phases is given specific procedural and rather formal form" (Eriksson \& Kovalainen, 2008, p. 156). New discoveries are always the result of high-risk, yet systematic and cognizant expeditions into unknown territory (Suddaby, 2006), and GT is an excellent fit for discovering theory grounded in the real world using both qualitative and quantitative data.

As its name suggests, GT is a recommended methodology for building and elaborating theory on multilayered, multifaceted, and dynamic social processes such as those frequently encountered within the domain of IB. GT involves analyzing any kind of data to discover theory, as its dictum is "all is data" (Walsh, Holton, Bailyn, Fernandez, Levina, \& Glaser, 2015, p. 6). Many perspectives of GT have emerged since the discovery of GT, but they are all united in their aim to generate new ideas and concepts rather than to test them. A phenomenon is noticed, researched, analyzed, theory is discovered, and then hypotheses are formed. GT is about data emergence following in-depth analysis of behavior rather than statistical significance of performed notions. It involves creativity, imagination, reflection, and the ability to think conceptually and abstractly (Glaser, 1999). As such, our main goals are to establish ground for the relevance of GT to IB research and provide guidance on how to build and elaborate theory in IB using GT. In the process, we make several unique contributions.

First, we briefly discuss what theory is and describe the premises and elements of a theory. Second, we further establish the need for theory building within IB. Third, we 
describe how GT can be used to build theory in IB via discussion of two studies that follow GT principles for theory building. In essence, we highlight to IB scholars what is theory, what are its premises and elements, and provide clear guidelines on how to develop and elaborate theory in IB using GT. While other researchers have successfully applied GT in IB research, our manuscript aims to further establish the relevance of GT to IB, provide clear guidelines to IB researchers, and encourage the use of GT within the IB domain. In addition, we contribute to future theory development by identifying specific areas within IB where GT can be applied and the type of research questions that can be addressed using this methodology. Importantly, throughout the manuscript we highlight that both qualitative and quantitative data can and should be used within GT. Finally, we present a discussion of the limitations of GT for IB theory building.

\section{THEORY BUILDING IN IB}

\section{Theory and Theory Building}

Theory plays a crucial role in conducting research and advancing knowledge (Bello \& Kostova, 2012). Defined as a set of logical statements about how certain phenomena and constructs are related within a set of boundary assumptions and constraints (Bacharach, 1989), theory should have several merits to contribute to the advancement of a research field. First, a good theory should be clear and logically integrated (Hendrick \& Johns, 1972). Second, theory should provide original insights, have utility, be relevant to practice, and be prescient to live up to its contribution promise (Corley \& Gioia, 2011). Accordingly, theory should allow scientific knowledge to accumulate as to move up in the evolution of knowledge. Third, theory should enable describing, explaining, predicting, and ultimately controlling phenomena. Description, explanation, and prediction are intertwined building blocks of theory. In particular, description does not alone constitute a theory but is a 
necessary first step to establish a theory (Bacharach, 1989). Prediction is highly desired for controlling phenomena but is incomplete without explanation. Accordingly, theory is richest when it explains beyond description and prediction (Bacharach, 1989) and ultimately enables controlling phenomena. All these aspects of good theory constitute the foundation of much needed theoretical advancements in IB.

Seminal research on theory development indicates a complete theory must possess four critical elements (Whetten, 1989). First, the what aspect determines which constructs, variables, or concepts should be considered to explain the specific phenomenon of interest. Evaluating the extent to which the 'right' factors were included to develop a good theory requires sensitivity to the competing objectives of comprehensiveness and parsimony criteria (Dubin, 1978). Second, the how component addresses the question of how the elements relate to each other. During this step patterns are delineated and the relationships between concepts are typically introduced. At an operational level this stage involves drawing 'arrows' to connect 'boxes'. Combined, the what and how elements form the domain or subject of the theory (Dubin, 1978).

Third, the why aspect of theory building encompasses the underlying psychological, economic, or social dynamics that justify the selection of factors and the proposed relationships. The why defends the rationale and introduces and explains the theory's assumptions. Accordingly, it is the why that can be considered a very fertile area for theory development. In essence, it is the glue that holds the factors and the proposed relationships together. While the what and how describe a phenomenon, only the why explains. The why component is a key hallmark of rigorous and truly insightful theory development because it provides plausible and logical explanations for the theory. Combined, these three elements provide the essential criterion of a good theory: description and explanation (Dubin, 1978). 
Accordingly, the why component is a fruitful yet difficult component of theory development (Whetten, 1989), and is of particular interest to our paper.

Fourth, the who, where, and when place limitations on the proposed relationships, which result in mid-range well-grounded theory that is theoretically rigorous and contextually relevant (Kim, Stump, \& Oh, 2009) and is delimited to specific aspects of social phenomena (Eriksson \& Kovalainen, 2008). The answers to who, where, and when set the boundaries of generalizability and demarcate the range of the theory. This fourth aspect identifies the context and boundary conditions within which the proposed relationship ought to hold. Context sensitivity is primarily critical for theories based on experience (Gergin, 1982). Context informed theories are the core premise of IB and provide stronger explanations to IB phenomena (Wright, Filatotchev, Hoskisson, \& Peng, 2005), and theories that do not account for boundaries and contingencies are often deemed vague and constraint (Barreto, 2010).

An advantage of building theory from empirical research over building theory purely on conceptual basis is that theory derived from empirical research is more likely to be logically integrated, context-rich, realistic, insightful, and representative of the phenomena of interest. The resulting implications from such research are valuable to practitioners and others who want to understand the lived experienced of those involved in international business as opposed to idealistic theories that may or may not be generalizable to larger contexts. GT is "genuinely engaged with the world" (Fendt \& Sachs, 2008, p. 448). It enables identifying and examining issues that matter and involves building theory of phenomena as they occur. As such, it is typically superior to relying solely on deductive reasoning and intellectual craftsmanship (O'Reilly et al., 2012).

\section{Need for and Challenges of IB Theory Building}


Conceptual advances and theory building are critical to the vitality of a research field (MacInnis, 2011). Theory can envision new insights, relate previously fragmented or confounded insights, explicate less understood phenomena, or promote debate on unresolved issues (MacInnis, 2011). Accordingly, theory functions as a bloodline to research, especially to fields like IB that face tough competition over their position and relevance (Shenkar, 2004). New theoretical insights offer new ideas and research avenues to pursue and advance the knowledge in the field and provide guidance in doing so. Accordingly, there is a substantial need for theoretical advances drawing either on non-empirical conceptual studies or on exploratory empirical insights such as those from GT (Suddaby, 2006).

Researchers have persistently argued for the need for theory development within IB research (Grosse \& Behrman, 1992; Thomas, Cuervo-Cazurra, \& Brannen, 2011). Theory developed within IB field could serve well to further establish the distinctiveness and sustainability of IB as a field of research (Buckley, 2002). Likewise, IB faces an urgent need for a reevaluation of its core premises as well as implicit and explicit models because of fundamental changes occurring in the economy, society, and politics (Cavusgil \& Cavusgil, 2012).

We do not imply the field of IB does not have its own body of theories, frameworks, constructs and models. It most certainly does (e.g., theories of internationalization of the firm, theories of the multi-national enterprise (MNE), and others) (Bello \& Kostova, 2012). However, as the JIBS editors have recently emphasized, it is critical IB researchers aim to make a significant contribution to IB theory development primarily across the essential elements of theory (Bello \& Kostova, 2012). Importantly, theory building does not necessarily imply continuously generating a new theory from scratch, but also improving what already exists to refine theories and make them more relevant to practitioners. 
Despite the compelling need for theory generation in IB, several specific challenges hinder theory development. First, Bello and Kostova (2012) noted that especially multidisciplinary and contextual issues render unique challenges to the role of theory in IB, particularly in terms of conceptual clarity, depth, rigor, and utilization of the MNE as a unique research context while informing its substantial heterogeneity and complexity. Likewise, borrowed theories from other disciplines and business fields are often applied in IB without accounting for potential contingencies (Shenkar, 2004; Wright et al., 2005), limiting further theory development in IB. Second, another challenge of theory building and testing in the IB field has been the disproportional focus on "boxes", rather than "arrows" (Thomas et al., 2011). This limitation implies theory building efforts in IB research have been concentrated on concepts and linkages between them without deeper appreciation and explanation of the nature of the proposed relationships. Accordingly, many studies remain somewhat shallow in the treatment of the linkages between concepts.

Third, the study of international business, which focuses more on macro issues and has been relatively favored by JIBS, has been separated from the studies of international management, which has relatively more focus on managers (Teece, 2014). This has created theoretical voids, especially in terms of fragmentation of IB related research and insufficiency of research with human touch (Teece, 2014) that engages a phenomenon from the perspective of those living it (Corley, 2015).

Fourth, IB research has been relatively oblivious to microfoundational examination of relevant issues that could offer rich explanations and advance the body of knowledge in IB (Chan \& Makino, 2007; Morris, Hammond, \& Snell, 2014). The spreading recognition that business and management research should account for foundations rooted in individual action and interaction when building and testing theory (Foss, 2011), has not been fully echoed and enacted in IB. Finally, IB needs to avoid oversimplification of the environment via the 
rendering of a priori assumptions not anchored in reality (Shenkar, 2004) and develop more organic, conceptually rich lines of analysis. Though these challenges are not exhaustive of theoretical obstacles IB faces, they are primarily related to the domain of this paper.

Drawing on the need for and challenges of theory building in IB, it becomes evident that IB theory development should focus on theory building that is context-rich, behavioral, conceptually deep and rigorous, impactful, and can interweave various research streams and disciplinary paradigms within the IB field. As an underutilized methodology for building theory within IB, GT can be particularly useful for theory building and for addressing the above mentioned theory-related challenges IB faces. Reasons for this argument are discussed below.

\section{GT AND THEORY BUILDING}

\section{Defining GT}

Classic GT (i.e., as originally conceptualized by Glaser \& Strauss) refers to a general systematic research methodology of data collection and analysis that uses a systematically applied set of methods to generate a theory about a substantive area (Glaser, 1992). Though the GT methodology could be utilized for theory elaboration, its primary objective is to build mid-range theory grounded in empirical observations of words, actions, and behavior of the study's participants at various levels of generality (Goulding, 2002; Mello \& Flint, 2009). GT is predicated on the idea that "social science theory can be built from data systematically obtained in a social setting" (Robrecht 1995, p. 170). Given its nature, it is most suited for inductive research (Corley, 20015). Classic proponents of GT believe the proper application entails developing theories that enable explanation of behavior, are applicable in practice, and provide hypotheses that can be verified (Mello \& Flint, 2009). The power of GT partly stems 
from its potential to allow participants and researchers closest to the phenomenon to shape how it is studied (Corley, 2015).

Beyond being a method of data analysis as it is perceived by some scholars (Fendt \& Sachs, 2008; O'Reilly et al., 2012; Walsh et al., 2015), GT is a distinct full-fledged methodology with several interconnected components for building insightful and practical theory (O'Reilly et al., 2012). Accordingly, we view GT as an exploratory, reflective, flexible, and data centered methodology for theory building and elaboration; parts of which could be applied as a data collection and analysis method. However, it is important to motivate our argument and highlight the recent perspectives on whether GT is a method, technique, a methodology, a framework, or a paradigm (Walsh et al., 2015).

We concur with Corley (2015) that GT is a powerful methodology of inquiry able to utilize both qualitative and quantitative data, but it is not an all-encompassing research paradigm (i.e., the system of believes and practices shared by a group of researchers). Given the divergent proliferation of its applications as well as its continuous evolution, it is not practical to go back to GT's roots and form a cohesive paradigm of GT (Corley, 2015). The plethora of different and sometimes conflicting understandings and applications of GT indicate GT is not really a paradigm. Likewise, GT's current relative incompatibility with deductive approaches hinders its potential as a paradigm, at least at this stage (Corley, 2015). However, it is possible GT might at some point in the future become a paradigm, but cannot be demoted to being method or technique either. GT is well beyond being solely a data collection (i.e., method) or data analysis (i.e., technique) tool (Walsh et al., 2015). In addition, current literature offers little support for considering GT as simply a framework (i.e., general set of guidelines a researcher may choose to follow in a certain project). In summary, though it could be too early to call GT a paradigm, it can be considered a well-recognized and valuable methodology for inductive and exploratory theory development (Corley, 2015). 
Next, we provide further support for positioning GT as a methodology by continuing the Walsh et al. (2015) dialogue and offering an approach for executing GT with quantitative data. This is an important extension to the dialogue and a noteworthy contribution considering quantitative data is predominant in IB research.

\section{Conducting GT with quantitative data}

According to Professor Glaser, GT entails the discovery of emerging patterns in data (Glaser, 1978). The plethora of GT books and articles offer guidelines on how to build theory and discover patterns in qualitative data, but little insights on how determine patterns in quantitative data (e.g., survey). We suggest fuzzy set/qualitative comparative analysis (QCA) as an example for conducting GT using quantitative data (Chang, Tseng, \& Woodside, 2013; Wu, Yeh, \& Woodside, Wu et al., 2014). QCA is not suggested as "the approach" to be followed when conducting GT using quantitative data, but rather as an example. This approach uses Boolean algebra rules to identify which of the attributes combinations, if any, act as sufficient or necessary conditions for the outcome (Fiss, 2007). QCA acknowledges the influence of attributes on a specific outcome depends on how the attributes are combined. This approach can better drive GT quantitative data analysis because it guides the investigator to account for contrarian cases and go beyond simply pointing out the main effects observed in multiple regression analysis.

Within QCA, contrarian case analysis indicates that although the data might provide adequate statistical support that $\mathrm{X}$ is positively associated with $\mathrm{Y}$, the same data set can include cases of high $\mathrm{X}$ and low $\mathrm{Y}$ and cases of low $\mathrm{X}$ and high $\mathrm{Y}$. As such, complexity theory helps researchers move beyond the dominant approach of using multiple regression to examine net effects and interaction terms. Accounting for contrarian cases can provide novel and insightful perspectives on the relationships between the variables of interest (Woodside, 2014). For example, traditional regression analysis might indicate in a study that the number 
of hours students spend studying each week is positively associated with their respective exam grades. QCA can help identify in the same data set cases where subjects who spent few hours studying and still achieved high exam grades. QCA helps determine how combinations of the low hours spent studying variable with other variables (e.g., high/low intelligence, high/low GPA, high/low parental support) can still lead to high exam grades. In essence, QCA helps determine patterns in quantitative data and reveals various combinations of variables (highs and lows) or "recipes" that lead to the same outcome.

Determining patterns in data facilitates the emergence of theory. GT aims to develop theory grounded in data, as such QCA can be applied within GT to establish patterns in quantitative data and help facilitate theory building. QCA aims to provide a rich description of the complex relationships between a set of variables and can therefore be successfully employed when conducting GT. It is beyond the scope of this article to offer a detailed description of the QCA process, therefore we refer the readers to the Woodside (2014) and Wu et al. (2014) articles as more recent, relevant readings that provide step-by-step guidelines on how to conduct QCA. We believe the use of QCA for the analysis of quantitative data can expand and facilitate the rigorous application of GT to quantitative data and help further establish GT as a valuable methodology for IB theory development.

\section{GT and extant theory}

Extant theory and GT have a complicated relationship (Locke, 2015). Starting a research study from a completely atheoretical standpoint is neither feasible nor practical (Dunne, 2011), and approaching a phenomenon as purely new with a "blank slate" is rare in business research (Locke, 2015). Even if researchers do not directly use theory to guide their research, theory is embedded and enacted in their approaches, sense-making, world-view, and indirectly shapes their research. However, elevating theory at the expense of observations is incompatible with the nature of GT as an exploratory methodology (Walsh et al., 2015). 
Literature can help explore data more effectively via guided focus and elaborating and explaining findings without dampening the emergence process in GT as well as avoiding redundancy by informing about the research that has already been done (Locke, 2015). Thus, it would be beneficial to explore the different ways in which theory and observations may relate in GT and potential tradeoffs at the interface between extant theory and GT (Locke, 2015).

GT allows researchers to be creative and at the same time provides them with essential guidelines (Walsh et al., 2015). GT seeks to discover the meanings and concepts used by individuals in social settings and is based on the underlying assumption that people are continuous problem solving actors (Gephart, 2004) as opposed to reactionary actors. Understanding how people go about dealing with daily problems and how people interact when trying to solve problems is considered vital. One advantage of GT methodology is the flexibility it provides to researchers in conducting explorative research and building theory grounded in context (Gebhardt, Carpenter, \& Sherry, 2006).

GT seeks to develop theoretical concepts and relationships among them and is not bound to a particular unit of analysis, time, or place (Mello \& Flint, 2009). It also transcends the narrow way in which it is often applied, not only in data type used during research processes but also in the specifications that make it GT (Walsh et al., 2015). GT is well suited when (a) there is little theoretical knowledge exists about the phenomenon, (b) the researcher's experience and viewpoints are critical to the inquiry, and (c) the meanings and relationships of concepts are fragile (Sousa \& Hendriks, 2006; Suddaby, 2006). Accordingly, the key strength of GT resides in its potential to provide empirically grounded answers to the important questions of theoretical contribution such as what's new?, so what?, why so?, and well done? (Whetten, 1989). 


\section{Key GT Tenets}

Strauss and Corbin (1990); Glaser, 1978; and Glaser and Strauss (2009) are the primary sources for reading about how GT is conducted. Next, we describe the five core tenets of GT (theoretical sampling, constant comparison, theoretical coding, theoretical saturation, and theoretical sensitivity) as articulated by O'Reilly et al. (2012) and the relationships among these core tenets. Emergence of new and useful theory entails all these tenets of GT working together harmoniously through the interplays of data collection, data coding, data analysis, and iterative discovery (O'Reilly et al., 2012). This emphasizes that the full and systematic application of GT as a methodology is preferred to reap full benefits of GT in building relevant theory for IB, as opposed to its partial application such as a data analysis method to handle non-standardized qualitative data.

Theoretical sampling requires that decisions about which data to collect next are determined primarily by the theory being constructed (Suddaby, 2006). The respondents' answers and the emerging patterns and theory should shape the interviewer's subsequent questions and direct the research to the next participant. As the researcher makes memos, compares data, and retains theoretical sensitivity, the research should choose the next interview participant based on the emerging theory. This data collection process helps further refine the context within which the proposed relationship ought to work (Glaser \& Strauss, 1967; Strauss \& Corbin, 1990).

Constant comparison refers to continuously comparing codes, categories, ideas, and concepts in earlier and new data on the basis of their theoretical similarities and dissimilarities to enable adjustment of theoretical categories. Constant comparison allows the researcher to be sensitive to the data and the patterns that are appearing by comparing memos, codes, and incidents and forming relationships between the categories (Glaser \& 
Strauss, 1967; Gephart, 2004). Together with theoretical sampling, constant comparison enables engaging a phenomenon from the perspective of those living it (Corley, 2015). Failure in constant comparison can result in data analysis that is separate from coding and collection (O’Reilly et al., 2012).

Theoretical coding refers to a systematic process used to make sense of research data by categorizing and grouping similar examples from the data (O'Reilly et al., 2012). There are three commonly accepted types of theoretical coding: open/initial coding, axial coding, and selective/focused coding (Charmaz, 2006; Strauss, 1987; Strauss and Corbin, 1990). Each step of coding enables scholars to break data down further into categories and themes to examine the relationships within the data. The primary function of theoretical coding is its enabling role in the discovery of core concepts, relationships among them, and emergent theory. The use of memos are particularly important for theoretical coding and constant comparison. Memos are the researcher's way of tracking ideas regarding codes and their relationships as they emerge during theoretical sampling, coding, and analyzing (Glaser, 1999).

Theoretical saturation denotes the point at which no new information appears to emerge: the point when no new properties, conditions, and so forth could be attributed to a category (O'Reilly et al., 2012). Theoretical saturation is typically determined by the analysis of evolving data that entails theoretical coding in interaction with constant comparison within and across contexts (Goulding, 2002). It is pivotal for sturdy theory development as it enables completeness of categories emerging out of data (Goulding, 2002).

Theoretical sensitivity is an underlying attribute that entails theoretical understanding of the phenomenon of interest rather than relying on purist and unguided induction (Goulding, 2002). Theoretical sensitivity gives meaning to data and identifies data that have pertinent meaning to the emerging theory versus data that do not (O'Reilly et al., 2012). It is 
inclusively relevant to data collection, analysis, and write-up processes, and it requires the researchers to remain sensitive to the data (Glaser, 1978). Theoretical sensitivity unlocks one of the major advantages of the GT methodology that is the flexibility to alter research design on the basis of an evolving understanding of the change process and research context (Gebhardt et al., 2006).

These five discussed core tenets of GT are typically all relevant to three stages of data collection, analysis, and write-up of grounded theorizing. However, some of these stages are more relevant for each of the five core tenets than the others. Likewise, we conceptualize theoretical sensitivity primarily as an attribute a researcher should have along all processes of GT while the other four core tenets are essentially viewed as processes to be followed systematically.

Despite the broad application of GT, the methodology has oftentimes been misunderstood and misapplied. For instance, though original GT could be ontologically and epistemologically flexible and could involve quantitative research, various prevalent interpretations of the methodology have emerged and view GT as an interpretivist and solely qualitative method (Walsh et al., 2015). Likewise, there has been a growing gap between those who actually engage in GT and those who write about it, the former group following relatively pragmatist practices while the latter group adhering to purist idealism (Fendt \& Sachs, 2008). This gap is exacerbated by several perspectives of GT being promoted simultaneously by different scholars and a proliferation of how-to manuals and textbooks for simplifying and streamlining GT research (Fendt \& Sachs, 2008). A wide range of sources discuss GT as a method of data analysis rather than a comprehensive methodology and the majority of business and management research adopts it as a data analysis technique with a special focus on coding procedures (Eisenhardt \& Graebner, 2007; Gephart, 2004; O’Reilly et al., 2012). In this vein, we acknowledge and accept that various forms and purposes of GT 
exist. We further discuss its main perspectives to arrive at a fuller understanding of the methodology.

\section{GT Perspectives}

Since its discovery, GT has been continuously evolving (Dunne, 2011), and three major perspectives have emerged. The first GT perspective, championed by Glaser, promotes GT as abstract conceptualization that discovers a theory with flexibility and constant comparison of concepts (Glaser, 2002). Glaser believes the patterns from data emerge naturally creating a description of the participant's reality. He pays less attention to the process. For Glaser, the research problem is found through less rigid coding, theoretical sampling, and constant comparison (Glaser \& Strauss, 1967). Everything in the participant's world is data (Glaser, 2001) and discovering the theory through induction and emergence is key (Babchuk, 1996). Glaser's GT is more flexible, guided by informants (Babchuk, 1996; Glaser, 1992), and the purpose should be at discovering new hypotheses or theory (as opposed to verification) (Glaser, 1992). The greatest difference between Glaser and Strauss's versions of GT is verification (Charmaz, 2000) where Glaser stresses theory building while Strauss focuses on theory verification.

The second GT perspective, supported by Strauss and Corbin, emphasizes making analysis more systematic to establish preciseness and generalizability (Strauss \& Corbin, 1990; Strauss \& Corbin, 1998). Strauss and Corbin's work describes the cultural scene through more rules, believing the research question should describe the phenomenon to be studied thereby guiding inquiry (Strauss \& Corbin, 1990). Strauss's branch of GT showed elements of the quantitative paradigm with its approach as a methodology. Strauss believes in replication, interpretation with participants, generalizability, precision, and significance (Babchuk, 1996). While Strauss says induction, deduction, and verification are the essentials of GT (Strauss, 1987), others believe Strauss is actually promoting the use of abductive 
reasoning. Strauss wants to test all possible explanations through hypotheses that are confirmed or disconfirmed until the most likely interpretation of the data is reached (Bryant \& Charmaz, 2007). Accordingly, Strauss has allowed GT to develop and be formed by modern methodologies (Corbin \& Strauss, 2008).

The third perspective, constructivist, like Glaser's does not follow the strict rules of data analysis believing it erodes the potential for creating new theory (Charmaz, 2008). Research with guidelines constrains the conditions, thereby defining the phenomenon rather than letting the phenomenon define itself (Charmaz, 2008). In the constructivist branch, data is coconstructed between the researcher and participant as the researcher becomes a participant to share the experience. The phenomenon is prioritized and the researcher focuses on how the participant constructs meaning. Detailed descriptions are developed and stories are told in realization that as a researcher you cannot fully understand the viewpoint of the participant (Charmaz, 2006). The constructivist believes you can create theory but it is only an interpretation biased by the researcher. This view is similar to postmodernism where meaning is derived from language, culture, and symbols (Welch \& Piekkari, 2006). However, the focus of constructivism is on understanding how the participants create meaning, not just their description of the phenomenon (Charmaz, 2006). The methods used for this analysis are created within the process while the researcher inquires (Charmaz, 2008). While Charmaz (2008) states the constructivist view is about emergence, she repeatedly describes the meanings as being co-created, co-constructed, and formed by mutual interpretation (Charmaz, 2006; Charmaz, 2008; Glaser, 2002).

The three viewpoints of GT (Glaser's, Strauss and Corbin's, and Charmaz's) each have different goals in mind for the application of GT. Glaser's version is to conceptualize and build theory. The research problem emerges from inquiry and the flexible data analysis process of constant comparison allows the researcher to rely on more on induction and less 
on deduction (Eriksson \& Kovalainen, 2008; Walsh et al., 2015). Glaser's GT privileges phenomena over a priori academic theory (Walsh et al., 2015) and allows limited and meticulous use of literature (Dunne, 2011) to generate theory. Strauss and Corbin set out to understand the process the phenomenon happens through (Corbin \& Strauss, 2008; Strauss \& Corbin, 1998). The constructivist view places a higher emphasis on accurate description and flexibility of the process (Charmaz, 2000; Charmaz, 2014; Glaser, 2002).

Glaser endorses theory development through constant comparison and emergence that necessitates the researcher remains open to what is discovered empirically in the area under investigation (Walsh et al., 2015). Research using Glaser's GT has no set process but allows the theory to be created from the data. Glaser's approach avoids verification and methods which may leave users confused and lead to "theory" that is not grounded in the data. His approach is more flexible but the lack of rules or guidelines leaves a researcher with a broad design that may overwhelm the research. Results may not be focused or specific enough to be useful. The lack of process may slow a researcher down as s/he explores every avenue and the research question may not be fully answered. As such, this version of GT is best suited for broad questions about phenomena that are less specific in nature.

Strauss and Corbin's use of rules allow for replication, generalizability, and verification of data through a more objective lens. The specifics of defining a core category help guide the researcher toward theoretical understanding and theory building (Charmaz, 2006), but the strict adherence to rules could cause loss of important data and theory that do not fit directly into a core category (Charmaz, 2006; Glaser, 1992). While the rules give structure, the guidelines could make data analysis more difficult and take the researcher down the wrong path (Heath \& Cowley, 2004) by having the researcher look for data rather than at data (Robrecht, 1995). In Strauss and Corbin's approach to GT, the data analysis process could have the researcher looking for parts that fit the code rather than interpreting the data for what 
it really is. Corbin and Strauss (Corbin \& Strauss, 2008; Strauss \& Corbin, 1998) argue that sometimes researchers do not need to build theory but form useful descriptions. They believe their use of GT goes beyond building theory and encompasses theory elaboration. This methodology is also more useful when a research question is more specific at the beginning and the researcher desires an answer to a particular question (as opposed to letting the data create multiple research questions).

The constructivist allows for more flexibility in theory creation but acknowledges the subjectivity of the researcher's viewpoint is found in the results. Fewer rules allow for more data emergence but also allow for more error. While it can allow for broader findings, the lack of specificity could be problematic for the applicability of results to future endeavors. The constructivist view merges the participant's definition of the phenomenon with that of the researcher. While the constructivist view allows for greater flexibility, researchers in this paradigm have to be careful the participant's view of the phenomenon does not become overly biased by the researcher rendering the description formed as inaccurate. This methodology is useful for generating descriptions that may be more relatable to a wider audience but the description may not be fully what a participant experienced. This methodology is best suited for cross-disciplinary research and creating links between meanings, which is consistent with Burgelman's (2011) viewpoint on the usefulness of GT. Next, we will illustrate how GT can be employed to build theory via examples of past research following GT.

\section{Examples of Past Applications of GT for Theory Building}

GT has been applied for theory building across a wide variety of disciplines and topics, ranging from the medical discipline to various business fields such as organizational behavior, management, and marketing (Goulding, 2002). Among other business and management fields, GT has been successfully, but scarcely, used for theory generation within 
IB (e.g., Hamel,1991; Kotabe, Parente, \& Murray, 2007). Researchers in other business and management fields, such as marketing (e.g., Gebhardt et al., 2006; Palka, Pousttchi, \& Wiedemann 2009), management and organization studies (e.g., Pratt, Rockmann, \& Kaufmann, 2006; Ravasi \& Schultz, 2006; Volkoff, Strong, \& Elmes, 2007), and strategic management (Bansal, 2005; Paroutis \& Heracleous, 2013) also use GT for theory development. We elaborate on two GT studies by Gligor and Holcomb (2013) and Kotabe et al. (2007) to illustrate how GT can be applied for building and elaborating theory in IB.

Gligor and Holcomb (2013) employed GT to build theory that describes how buyers and sellers of logistics services interact within the context of personal relationships that are themselves embedded within inter-firm relationships. Although supply chain relationships have been studied extensively, Gligor and Holcomb (2013) used GT to address the lack of theory addressing the behavioral complexities that emerge through the personal interactions of supply chain members. This indicates that GT can be used for theory development as well as theory extension.

Gligor and Holcomb (2013) show how grounded theory can be used to generate theory for a field and present clear evidence that GT principles were followed throughout the research process. At the outset it is evident that the topic lends itself to GT as it deals with dynamic and complex human behavior that is context specific. The authors use theoretical sampling to collect future data based on the emerging theory from collected data (Strauss and Corbin, 1990). They clearly highlight that the respondents' answers and the emerging patterns and theory informed subsequent data collection. The authors interviewed only managers who had experience with the phenomena of interest and their counterparts in order to create a dyad in which relationships could be assessed. The researchers then determined who to interview next based on who could give them information not yet received to further expand upon the emerging theory. Each new interview further shaped the data collection 
effort. This is very distinct from other data collection approaches, as some allow all the data to be collected at one point in time. Interviews stopped only when theoretical saturation was reached. Theoretical saturation was determined by data analysis (e.g., theoretical coding in interaction with constant comparison) (Goulding, 2002) and is another distinct feature of GT and ensures redundant data is not collected. Data is considered redundant when concepts repeat themselves and no new information is being collected.

As data collection continued and future samples were selected, constant comparison generated theoretical concepts that were not constrained by strict coding practices (Glaser, 1992). While data collection was in process, the authors analyzed each interview following theoretical coding guidelines. These guidelines make GT distinct because they provide a clear process researchers can follow to analyze data. While still allowing complete freedom to conduct exploratory research, these guidelines facilitate the emergence of categories and consequently, theory. In particular, three different types of theoretical coding were followed: open coding, axial coding, and selective coding (Strauss, 1987; Strauss and Corbin, 1990). Each step of coding allowed the authors to break the data down further into categories and themes to examine the relationship between the data. In the final stages of coding, the authors were able to limit the variables to only those relating to the core variables emerging. In the Gligor and Holcomb article, this coding resulted in the discovery of several actions that led to enhanced trust, communication, understanding, and business volume through the business relationship. The authors broke down their data in a sequential process to refine the data into a thematic model explaining the role of business friendships. The authors maintained theoretical sensitivity throughout their process to give meaning to data and identify data that have relevant meaning to the emerging theory versus data that do not (O'Reilly et al., 2012). In addition, the authors clearly linked the emergent categories to their data and provide adequate data evidence supporting the proposed theory. As such, this article is a good 
example of how GT can be executed in a manner that makes it clear to the reader that GT principles were indeed followed.

Only a limited number of IB studies have employed GT (e.g., Danis \& Parkhe, 2002; Gupta, Banerjee, \& Gaur, 2012; Kotabe et al., 2007; Maznevski \& Chudoba, 2000; Zhang, Farh, \& Wang, 2012). As such, the field has benefited very little from the methodology's ability to facilitate theory development and extension. When done well, the use of GT in IB research can result in theory generation that will lead the field into new territory. For example, Kotabe and colleagues (2007) used a grounded theory approach to examine the process of modular production in a specific industry, however they do not specify which grounded theory tradition was followed making it difficult for readers to understand which principles are being applied. It is also confounding that the article proceeds with a rather substantial literature review, while Glaser argues against conducting too much literature at the beginning of a study because it could bias the researcher, and therefore impede the emergence of theory from field data. According to Glaser, the literature review should only be conducted to help the researcher gain theoretical sensitivity (researcher's knowledge, understanding, and skill which foster the generation of categories and properties and increase the ability to relate them to emergent theoretical codes).

The authors used cross-comparison and constant comparison to ensure the results were consistent with their interviews and data. From their analysis, they were able to generate constructs applicable to their phenomenon and theoretical understandings. In examining this article with Whetten's (1989) framework, readers can see how grounded theory answered the theoretical questions of what, how, why, who, where, and when to focus theory generation. The "who", "where", and "when" questions are answered first as these apply to who is interviewed, what context the phenomena is occurring in, and what time frame is being examined. The researchers interviewed managers of the supply chain, production operations, 
and car design to gain broad perspectives. This resulted in 34 executives: 19 operational managers or supervisors, ten suppliers, one professor, and four other executives across four automaker companies in three countries. While the broad scope of interview participants allows theory to emerge that is generalizable and applicable to multiple contexts, the authors do not mention if additional data was collected after data analysis began leaving room for the reader to question if the sampling process followed the GT guidelines of theoretical sampling.

As the data is analyzed and constantly compared, the "what" of theory generation will come to fruition. Researchers will start to see themes and patterns that identify important constructs in the theory. Kotabe et al. (2007) indicated that degree of modularization, positional advantage/ performance, physical proximity, and degree of media naturalness were all constructs that emerged through the grounded theory process. In addition, several market factors became apparent, such as changing needs, labor unions, and firm specific factors like technology transfer, entrepreneurial intent, and perceived risk. All of these variables were identified as themes and interview quotes were used to provide support for the authors' interpretation of the data. For example, to justify the inclusion of entrepreneurial strategic intent, the authors include the following quote "This project incorporates the latest technologies and knowledge that GM learned in terms of production from all their plants around the world....this is really a pioneering project for GM." The authors offer multiple quotes from different interviews for each construct so the reader can understand why the constructs were included. However, they do not mention if constant comparison was employed nor how the data was analyzed to allow theory to emerge. The reader is only told that typical analysis employed in inductive research was followed and four individual case studies were developed. Grounded theory was actually developed in response to such methodological shortcomings and warranted criticisms of qualitative research approaches that 
lack reference to the exact methods the naturalist researcher employed to formulate theoretical explanations about the investigated phenomena (Robrecht 1995).

The authors then offer answers to the "how" and "why" by connecting all the constructs and generating propositions. For this part of the theory generation process, the authors combine the interview data with extant literature. Kotabe et al. (2007) found several research articles that state modular production integrates knowledge at the supplier level helping to reduce cost and improve positional advantage (Day \& Wensley 1988; Kotabe et al., 2007; Lanctot \& Swan, 2000; Quinn, 1999). The authors combine this literature with their findings of modular production being able to reduce inventory and delivery, resulting in reduced investment and costs. Through this process, the authors are answering how the variables are related and why the specified constructs relate to each other in the proposed way. Although the resultant propositions finalize the theory generation process by addressing the 'who, when, where, what, how, and why' elements of theory, the authors did not detail the methods in which they answered the questions and did not provide evidence that GT guidelines were followed. Next, we propose a deeper discussion of the areas where GT can be applied to generate IB-specific theory.

\section{APPLICATION OF GT FOR IB THEORY BUILDING}

We have established the need for theory building in IB and briefly discussed theoretical challenges the field faces. We have also introduced GT as a distinct methodology for theory building by informing readers with its brief overview, five core tenets to be followed when adopting GT, and its three major perspectives as well as offering two examples of an application of GT for theory building. Drawing on these lines of discussion, we move on to the discussion about the specifics of using GT in IB and types of data and 
theoretical problems GT is suited for solving to illustrate where GT can make a contribution to IB research.

Referring back to the premises of good theory, GT is particularly useful in studying behavior and change (Corley, 2015; Goulding, 1998), understanding problematic, intricate, and little known social phenomena, and being flexible to allow theory to emerge from data (Mello \& Flint, 2009). GT is likely to boost originality, insightfulness, and utility of IB theory, since it enables the emergence of a detailed account of sophisticated real-life phenomena grounded in data. The uniqueness and the value of GT stem from being a methodology specifically crafted for building and elaborating theory through rich, in-depth, and explanatory stories of social and behavioral phenomena using any type of data. This often leads to a more realistic, relevant, and useful account of the phenomena of interest rather than relying on deductive reasoning and purely intellectual efforts or qualitative approaches, which enable developing good descriptions but remain weak on developing theories (O'Reilly et al., 2012). Many IB phenomena involve people actively solving social and behavioral problems, interpreting, reacting to, and trying to influence the diverse environments they are embedded in which can be addressed via GT. In IB, GT can have a wide and fruitful application to research by extending exploratory research and building frameworks that represent the underlying processes surrounding the phenomenon of interest. We identified a number of key yet non-exhaustive research areas and challenges within the IB domain that could benefit from the application of GT.

Explicating the arrows. Thorough explanation of theoretical relationships is essential to making a substantial theoretical contribution to the IB field (Thomas et al., 2011). Explicating the "arrows" offers better stories of the proposed relationships. Likewise, it accounts for the time dimension and introduces the experiences and viewpoints of the participants (Sousa \& Hendriks, 2006). In contrast, the overlook or shallow treatment of the means justifying and 
explaining the nature of proposed relationships between the constructs can lead to theories that lack substantial explanatory power (Thomas et al., 2011). Solely understanding the direction and strength of the "arrow" does not enable a comprehensive understanding of the nature of the relationship between the variables of interest (Coleman, 1990). A fuller understanding entails much deeper analysis and can be achieved with GT (Walsh et al., 2015).

GT can be utilized as a remedy against the challenge of limited explanations to important relationships. Many conceptual relationships are characterized by rather dynamic, sophisticated, and problematic processes and mechanisms that are well suited for GT. Some studies fail to illustrate the mechanisms and dynamics that explain the relationship between A and $\mathrm{B}$, resulting in limited explanations of the focal relationship and failing to offer insights beyond simplistic statements like "A is positively associated with B". GT can provide genuine insights into the true nature of linkages of interest and help avoid potential future inconsistent findings concerning the nature, strength, and direction of a relationship. In this vein, GT can facilitate longitudinal research in generating novel conceptual frameworks that establish bridges between historical narratives and reductionist models and illuminate social systems characterized by complexity and nonlinear causation (Burgelman, 2011). Such utilization of GT can also increase the chance of IB research offering higher managerial relevance by developing lucid explanations to complex issues that matter to managers.

An interesting way to explicate arrows linking concepts would be to focus on practices of managers and employees as processes that engender and shape conceptual relationships. For example, recent research suggests that the investigation of the linkage between human resource management and performance would benefit from an actor-centric approach and a focus on activities (Björkman, Ehrnrooth, Mäkelä, Smale, \& Sumelius, 2014). Applying that reasoning to IB research, GT can unleash further insights into the linkages between human 
resource and organizational identity, alignment, and performance across MNE subsidiaries by examining the relationships from the actors' perspective. This can reveal the dynamics at the interface between praxis, practitioners, and practice and improve understanding on how decisions are made, implemented, enacted, and interpreted in MNEs (Björkman et al., 2014).

Interweaving interdisciplinary insights. Multidisciplinary in scope and interdisciplinary in content and methodology are distinct features of IB research (Thomas et al., 2011). Such interdisciplinary content allows examining a certain phenomenon through multiple angles, offering broader spectrum of understanding when describing, explaining, and predicting a phenomenon of interest. However, this feature of IB also creates a challenge in bringing diverse and fragmented insights together in a clear, cohesive, and consistent whole (Bello \& Kostova, 2012).

A deeper and up close understanding of phenomena is one of the primal means to achieve clarity and coherence and avoid inconsistency (Birkinshaw et al., 2011). Theory built via GT can function as an interweaving thread for fragmented interdisciplinary insights into a phenomena. The in-depth nature of GT methodology allowing researchers to obtain firsthand and ingrained appreciation of the research issue can help bring multiple perspectives together, resolve inconsistencies, and bridge disconnections between them.

For example, studying the changing dynamics of the interplay between the marketing function and the organizational environment within MNEs could interweave insights from marketing, organization studies, and IB. As Corley (2015) points out, GT is very useful for studying organizational change. GT can respond to the need for interweaving and integrating interdisciplinary insights to advance the knowledge in IB domain by examining change in marketing vis-à-vis the organizational environment of MNEs.

Elucidating microfoundations. Grounding macro and meso IB phenomena in their microfoundations is another research aspect that needs attention (Chan \& Makino, 2007; 
Morris et al., 2014). Though macro and meso analyses of phenomena of interest are quite common in IB, their roots in individual characteristics and behaviors are not fully understood. Nevertheless, through multi-level examination of phenomena researchers can account simultaneously for the influences of multiple actors and entities represented by different levels of analysis on a given phenomenon. Specifically, the examination of the microfoundations of the phenomena of interest enables researchers to account for individuallevel heterogeneity, individual behaviors that underpin macro constructs, characteristics and behavioral roots of strategic dynamics, and the potential mediating or moderating roles of micro-mechanisms related to behaviors in the linkages between macro variables (Foss, 2011). A better understanding of microfoundations can also help bridge the divide between international business and international management (Teece, 2014).

Understanding microfoundations entail human touch and embeddedness in the research context. Rich insights into the microfoundations of many IB issues that are researched but remain mysterious or dubious could be gained through GT by gathering data from participants who experience the phenomena being studied (Denzin \& Lincoln, 1998). GT is well suited for inductive examinations seeking deep insight into a phenomenon (Corley, 2015) that could enable elucidating microfoundations of some behaviorally complex managerial phenomena in IB that remain mysterious. GT can be particularly useful in acquiring early and exploratory insights into the microfoundations of important theoretical relationships marked by social actions and interactions (Denzin \& Lincoln, 1998; Mello \& Flint, 2009).

For example, the link between social capital and innovation has been researched extensively. However, in-depth and grounded explorations of the microfoundational mechanisms underlying this link in the MNEs context through GT can reveal rich and useful insights. GT can be a very useful approach for gaining insight into the complexities and 
intricacies of the firm especially with regard to microfoundational behavior, and it allows answering the question of "why" and "how" that are critical for research on microfoundations (Corley, 2015; Foss, 2011). Accordingly, even if we know that social capital, whether it is accumulated from local or foreign sources, is on average positively associated with innovation, GT can enrich our understanding by allowing to discover the microfoundational mechanisms, processes, and conditions of the MNE that not only engender the relationship but also sophisticate it.

Utilizing context. Context arises as both an opportunity and a challenge for the IB field. It is an opportunity, because it enables distinguishing IB from other business and management fields. It is also a challenge because a shallow and simplistic view can generate problems in developing IB theory (Bello \& Kostova, 2012). Accordingly, Bello and Kostova (2012) called for a more meticulous and systematic treatment of context in IB through conceptual distinctiveness across contexts, incorporation of substantial heterogeneity and complexity within the MNE context, and re-specification and alteration of the basic logic of dominant models for mono settings.

We posit that GT can be a proper methodology to meet these suggestions and utilize context for theory building and elaboration by moving beyond a shallow and simplistic view of context and elevating its level of sophistication. A renowned feature of GT is that it allows researchers to be immersed in their research context (Fendt \& Sachs, 2008; Walsh et al., 2015), and it is also well suited for inductive and explorative studies seeking to understand a phenomenon's connections to the context (Corley, 2015). It allows sense-making within the research context from the participants' perspective, which can further enrich and deepen the role of context in the generated theory. GT enables researchers to be very close to and embedded in their research context. 
There are many contextually embedded issues in IB that entail theoretical attention that could be addressed via GT. This methodology can unravel the theory building potential of IB and help the field achieve the status it deserves among other business and management fields through distinct context-specific theoretical contributions. An important concept that requires conceptual distinctiveness across contexts is value. Value defines the raison d'etre of marketing as a corporate function (Flint, Woodruff, \& Gardial, 2002; Woodruff, 1997). Thus, marketing strategy in IB boils down to the concept of value across borders (Flint, 2004), and IB could be viewed as the study of global value chains (Gereffi, Humphrey, \& Sturgeon, 2005). Given symbolism, sense-making, and subjectivity embedded in the pervasive concept of value (Flint et al., 2002), its understanding is highly contingent upon context (Flint, 2004). Context informed understanding of value can help enlighten many issues in IB such as market performance of MNEs, success of internationalization processes and foreign direct investments, interactions within international networks, and cross-cultural marketing that awaits in-depth exploration and resolution. Considering its ability to facilitate immersion into the research context and participants' mindset, GT can enable demystifying the concept of value through the insights of those experiencing the phenomenon across various contexts (Corley, 2015). Such a lively understanding of value and the role of the context can reinvigorate the concept within the IB research domain.

Developing theoretical boundaries and contingencies. Defining and clarifying theoretical boundary conditions and contingencies are important steppingstones for developing a good theory and avoiding vagueness and irrelevance (Barreto, 2010). In fact, defining the bounding assumptions enhances the utility of a theory by clarifying the limitations in applying the theory (Bacharach, 1989). Likewise, developing theoretical contingencies to the "grand" theories is valuable as well because it can help illustrate important integrative principles of 
such theories and explore internal and external factors that may enable (or inhibit) key relationships proposed by such theories (Barreto, 2010).

GT could be particularly useful in uncovering and scrutinizing boundaries and contingencies of grand borrowed/inherited theories within the IB context. This role of GT can particularly be viewed as more of a theory elaboration. By applying the core tenets of GT, researchers can elaborate theories and link them closer to IB. A deeper and contingent understanding of these important and complicated relationships can come from gathering data from participants who experience the phenomenon being studied as the nuances and specifics of a phenomenon may be missed by a researcher who is not immersed in the phenomenon and is not aware of all the intricacies involved.

For example, conflict is a multifaceted concept and is an inevitable component of relationships among socioeconomic entities (De Clercq, Thongpapanl, \& Dimov, 2009). Its prominence is exacerbated in international contexts due to cross-national differences (Morris, Williams, Leung, Larrick, Mendoza, Bhatnagar, Li, Kondo, Luo, \& Hu, 1998). Conflict may have various influences on relational and performance related outcomes under different conditions. Complexity and heterogeneity of conflict as well as conditions in which it is manifested entail GT for the in-depth exploration of the contingent relationships between various types of conflicts in various multinational settings (such as international joint ventures, alliances, and multinational networks) and performance and relational outcomes. Such rich contexts, the multitude of potential contingencies and boundary conditions for the relationship between conflict, and its relational and performance outcomes can be successfully addressed by GT.

Conducting exploratory/inductive quantitative research. Given its asymmetrically extensive application for qualitative versus quantitative research, GT has often been assumed to fit solely qualitative research. Recent works (Glaser, 2008) and commentaries (Corley, 
2015; Walsh et al., 2015) debunk this myth. Nonetheless, questions remain on how and for what types of quantitative research GT can be applied. In this paper, we suggest that IB research can utilize GT to build theory through quantitative research, and in addition to the QCA approach suggested earlier, we use big data as an illustrative case.

GT offers opportunities for novel utilization of quantitative data especially for exploration and theory building (Glaser, 2008). Exploration leads to new research questions, and without exploration it is difficult to ask the right questions. Thus, there is a need for more exploratory approaches even for quantitative research. On the data collection front, GT can allow asking inductive research questions and much needed exploratory, unrestrictive, and flexible quantitative data collection for theory building (Glaser, 2008). On the data analysis front, GT can instill human judgment and educated, yet exploratory, analysis and interpretation of data to make discoveries (Walsh et al., 2015). GT enables complex approaches to IB research, as the IB phenomena we face are often too complex for a mono-method, mono-data approach (Corley, 2015), especially when considering challenges of solely employing qualitative research.

The recent and trendy phenomenon of big data (i.e., large data sets collected over longer periods of time from large number of participants) could be a good example for the potential use of GT for conducting exploratory/inductive quantitative research. Limiting utilization of big data only to hypothetico-deductive approaches and shallow analyses may be less fruitful (Strong, 2015). The reductionist view suggesting full predictability of human behavior based on detailed and extensive data points fails to recognize it is often not possible to achieve such an objective given the complexity of human behavior (Strong, 2015). Such perceptions and use of big data can result in reducing its potential merit for research and applications (Strong, 2015). Big data is powerful only when supported by human judgment (Simpson, Meredith, Boyer, Dilts, Ellram, \& Leong, 2015). GT can respond to such challenges and the need for 
'humanizing' big data enables it to account for the complexity of the world we live in and the rich contexts in which socioeconomic entities behave. GT can facilitate making sense of unexpected findings, changes, and deviant cases (Corley, 2015) to uncover the true value of big data and humanize it (Strong, 2015) in the face of an increasingly digitalized and reductionist world.

In addition to the specific topical challenges IB faces, GT can also be used to address a data related challenge: conducting exploratory research for theory building involving (large) quantitative data. These are a few examples within IB that could benefit from a GT approach. They are not meant to be exhaustive, but rather illustrative of where GT could be applied and what types of questions or topics GT can be useful. Phenomena dealing with relational, cultural, and behavioral aspects in IB are particularly well suited for GT application. Also, whenever theory surrounding a phenomenon is sparse, GT can provide substantial benefits.

\section{Caveats and Limitations of GT}

General caveats and limitations. In 2006, Suddaby summarized several misconceptions about GT. Many use GT and its "flexibility" as an excuse to ignore literature and method. While some proponents of GT encourage using an open minded and flexible coding, the end result should always be tied back to literature. Otherwise the very benefits of GT's flexibility could vanish, and GT's identity as a distinct methodology for theory building could be jeopardized. There must be a systematic and meticulous approach to collecting and analyzing the data. GT's full application requires considerable time and intellectual effort, including being sensitive and diligent in following the tenets of GT to develop theory with rigor. However, despite being a sophisticated methodology (Eriksson \& Kovalainen, 2008), GT is not mechanical. There are guidelines to help the researcher but rules should be conducive to the emergence of theory. The methodology requires creativity and interpretation along with a systematic approach (Suddaby, 2006). 
GT can be misapplied when it is used beyond or outside of its purpose. GT is not best suited to test hypotheses or for areas of research that have already extensively progressed (Mello \& Flint, 2009; Suddaby, 2006). It is also not easy (Suddaby, 2006) and not a process to be rushed (Mello \& Flint, 2009), which could be daunting espeically for reseach in multiple context as IB often requires. The current literature regarding GT suggests a researcher will be criticized for the choices s/he makes with regard to the perspectives of GT. While some researchers believe GT is misapplied when classical traditions are mixed with modernist perspectives (O'Connor, Netting, \& Thomas, 2008), advancements in other disciplines through mixed GT techniques tells us IB research can be further advanced by doing just that. Failing to follow recent conversations on continuously evolving GT and to allow some novelty and flexibilities with its application can hamper its utility for building good theory in IB.

Caveats and limitations specific to IB. There are also several specific caveats and limitations of applying GT to IB research beyond the general ones that could be relevant to IB. First, application of GT with regard to context is a double-edged sword. GT requires researchers to be immersed in their research context which results in researchers having to spend considerable amounts of time when conducting IB research that follows GT, especially if the research is conducted in several countries. Theoretical sampling, constant comparison, and theoretical coding coupled with theoretical sensitivity and theoretical saturation entail considerable challenges, further exasperated when crossing country boundaries. For example, access to a sample that allows true theoretical sampling and saturation could become exponentially difficult in a multiple-country research study. Such challenges could make proper application of GT rather daunting. In turn, IB researchers may find themselves relying on a less than perfect application of GT and may decide a different approach is better suited to their circumstances. GT, when employed correctly and in the right situation, can be very 
beneficial. However, GT is not always the best option. The methods and techniques a researcher uses should be driven by the research question of interest.

A second major challenge of applying GT to IB research is affiliated to cultural and language issues that are attached to the multiplicity of research settings. To begin with, researchers are likely to face etic-emic dilemma when applying GT for cross-cultural research (Davidson, Jaccard, Triandis, Morales, \& Diaz-Guerrero, 1976), as it will be more difficult for researchers with mono-cultural background to habituate into a research setting that it is not their own. Likewise, contradictions between data collection techniques of "guest researcher(s)" and cultural practices of local research participants are potential challenges in the application of GT to IB research (Charmaz, 2014). The same could be evident with potential contradictions between data collection techniques and cultural practices of multicultural research groups that pose a threat to the validity and rigor of theory grounded in multiple contexts. Furthermore, Charmaz (2014) identified tensions between coding in English and native languages, points of cultural convergence and grounded theory strategies, and local constraints as additional caveats researchers should be aware of when engaged in GT research in international settings.

\section{CONCLUSIONS}

The field of IB is in need of more theory development (Morck \& Yeung, 2007). As new IB phenomena emerge, new theories are needed to answer the resulting research questions (Griffith, Cavusgil, \& Xu, 2008). As such, the main focus of our manuscript was to provide guidance on how to build IB specific theory using GT.

We make several important contributions to the field of IB. First, we provide a detailed description of the premises and elements of a theory. This helps IB researchers address various aspects of theory building and establish the ground for developing insightful theories 
by following GT. Additionally, we further establish the need for theory building and elaboration within IB and identify relevant theoretical challenges IB faces that could eventually be addressed by employing GT. This is intended to highlight the current theoretical limitations within IB and serve as another reminder on the importance generation IB theory.

Furthermore, we define GT, discuss recent developments surrounding its understanding and application, and make a key contribution by providing guidelines on how GT can be used to build and elaborate IB theory. We highlight though GT may be perceived as a technique, method, framework, methodology, or paradigm (Walsh et al., 2015), we view it as a methodology that could be applied for both qualitative and quantitative research. We also suggest scholars should be clear whether they adopt GT holistically or as a data analysis method, but in any case should pay attention to its five core tenets. In essence, we emphasize to IB scholars what is theory, what are its elements, and provide examples on how to deploy core tenets of GT for theory building and elaboration. This effort is intended to provide IB researchers with a blueprint of the process for developing and elaborating IB-specific theories.

Moreover, we contribute to future theory development by identifying areas within IB where GT can be applied and the type of research issues that can be addressed using this methodology. This helps illustrate the types of IB phenomena where theory building can be successfully accomplished using GT. This effort is intended to spur further interest in the development of IB theory. Finally, we make a noteworthy contribution by discussing some of GT's caveats and limitations, particularly those relevant to IB. This helps highlight to IB researchers the potential pitfalls and misconceptions that can be encountered when employing this methodology for theory building. 
It is important to conclude by emphasizing that it is unlikely a single or disparate study employing GT can lead to the emergence of important IB theories. In order to generate such theories, sustained efforts and multiple studies on the phenomenon are required. Rigorous IB theory can only be developed over time and would certainly benefit from the combined efforts of multiple studies by multiple researchers investigating the phenomena of interest around which theory development is deemed necessary. Therefore, in order to ensure the development of IB specific theory, we urge IB researchers to collaborate and focus their sustained efforts on conducting multiple studies using multiple methods to investigate IB phenomena that are considered in need of theory development. Because GT can also be successfully applied to quantitative data, we hope researchers can rest on the convenience of following one methodology even for multiple studies. It is time to embrace GT as a solid methodology to build theory in IB. This is especially important for facilitating the emergence of important theories within IB and advancing the field. 


\section{REFERENCES}

Babchuk, W. A. 1996. Glaser or Strauss? Grounded theory and adult education. In Proceedings of the 15th Annual Midwest Research-to-Practice Conference in Adult, Continuing, and Community Education, 1-6.

Bacharach, S. B. 1989. Organizational theories: Some criteria for evaluation. Academy of Management Review, 14(4): 496-515.

Bansal, P. 2005. Evolving sustainably: A longitudinal study of corporate sustainable development. Strategic Management Journal, 26(3): 197-218.

Barreto, I. 2010. Dynamic capabilities: A review of past research and an agenda for the future. Journal of Management, 36(1): 256-80.

Bello, D. C., \& Kostova, T. 2012. From the editors: Conducting high impact international business research: The role of theory. Journal of International Business Studies, 43(6): 537-543.

Birkinshaw, J., Brannen, M. Y., \& Tung, R. L. 2011. From a distance and generalizable to up close and grounded: Reclaiming a place for qualitative methods in international business research. Journal of International Business Studies, 42(5): 573-581.

Björkman, I., Ehrnrooth, M., Mäkelä, K., Smale, A., \& Sumelius, J. 2014. From HRM practices to the practice of hrm: Setting a research agenda. Journal of Organizational Effectiveness: People and Performance, 1(2): 122-40.

Brannen, M. Y., Piekkari, R., \& Tietze, S. 2014. The multifaceted role of language in international business: Unpacking the forms, functions and features of a critical challenge to MNC theory and performance. Journal of International Business Studies, 45(5): 495-507.

Bryant, A., \& Charmaz, K. 2007. The Sage handbook of grounded theory. London: Sage. 
Buckley, P. J. 2002. Is the international business research agenda running out of steam? Journal of International Business Studies, 33(2): 365-373.

Burgelman, R. A. 2011. Bridging history and reductionism: A key role for longitudinal qualitative research. Journal of International Business Studies, 42(5): 591-601.

Cavusgil, S. T., \& Cavusgil, E. 2012. Reflections on international marketing: Destructive regeneration and multinational firms. Journal of the Academy of Marketing Science, 40(2): 202-217.

Chan, C. M., \& Makino, S. 2007. Legitimacy and multi-level institutional environments: Implications for foreign subsidiary ownership structure. Journal of International Business Studies, 38(4): 621-638.

Chang, C. W., Tseng, T. H., \& Woodside, A. G. 2013. Configural algorithms of patient satisfaction, participation in diagnostics, and treatment decisions' influences on hospital loyalty. Journal of Services Marketing, 27(2): 91-103.

Charmaz, K. 2000. Constructivist and objectivist grounded theory. In N. K. Lincoln \& Y. S. Denzin (Eds), Handbook of qualitative research (2nd edn). Thousand Oaks, CA: Sage.

Charmaz, K. 2006. Constructing grounded theory: A practical guide through qualitative research. London: Sage.

Charmaz, K. 2008. Grounded theory as an emergent method. In S. N. Hesse-Biber \& P. Leavy (Eds), Handbook of emergent methods. New York: The Guilford Press.

Charmaz, K. 2014. Grounded theory in global perspective: Reviews by international researchers. Qualitative Inquiry, 20(9): 1074-1084.

Coleman, J. S. 1990. Foundations of social theory. Cambridge, MA: Belknap Press.

Colquitt, J. A., \& Zapata-Phelan, C. P. 2007. Trends in theory building and theory testing: A five-decade study of the academy of management journal. Academy of Management Journal, 50(6): 1281-1303. 
Corbin, J., \& Strauss, A. 2008. Basics of qualitative research: Techniques and procedures for developing grounded theory. London: Sage.

Corley, K. G. 2015. A commentary on "what grounded theory is ...": Engaging a phenomenon from the perspective of those living it. Organizational Research Methods, 18(4): 600-605.

Corley, K. G., \& Gioia, D. A. 2011. Building theory about theory building: What constitutes a theoretical contribution? Academy of Management Review, 36(1): 12-32.

Danis, W. M., \& Parkhe, A. 2002. Hungarian-Western partnerships: A grounded theoretical model of integration processes and outcomes. Journal of International Business Studies, 33(3): 423-455.

Davidson, A. R., Jaccard, J. J., Triandis, H. C., Morales, M. L., \& Diaz-Guerrero, R. 1976. Cross-cultural model testing: Toward a solution of the etic-emic dilemma. International Journal of Psychology, 11(1): 1-13.

Day, G. S., \& Wensley, R. 1988. Assessing advantage: a framework for diagnosing competitive superiority. Journal of Marketing, 52(2): 1-20.

De Clercq, D., Thongpapanl, N., \& Dimov, D. 2009. When good conflict gets better and bad conflict becomes worse: The role of social capital in the conflict-innovation relationship. Journal of the Academy of Marketing Science, 37(3): 283-297.

Denzin, N. K., \& Lincoln, Y. S. 1998. The handbook of qualitative research. Thousand Oaks, CA: Sage.

Doz, Y. 2011. Qualitative research in international business. Journal of International Business Studies, 42(5): 582-590.

Dubin, R. 1978. Theory development. New York: Free Press.

Dunne, C. 2011. The place of the literature review in grounded theory research. International Journal of Social Research Methodology, 14(1): 1-14. 
Eisenhardt, K. M., \& Graebner, M. E. 2007. Theory building from cases: Opportunities and challenges. Academy of Management Journal, 50(1): 25-32.

Eriksson, P., \& Kovalainen, A. 2008. Qualitative methods in business research. London: Sage.

Fendt, J., \& Sachs, W. 2008. Grounded theory method in management research: Users' perspectives. Organizational Research Methods, 11(3): 430-455.

Fiss, P. C. 2007. A set-theoretic approach to organizational configurations. Academy of Management Review, 32(4): 1180-1198.

Flint, D. J. 2004. Strategic marketing in global supply chains: Four challenges. Industrial Marketing Management, 33(1): 45-50.

Flint, D. J., Woodruff, R. B., \& Gardial, S. F. 2002. Exploring the phenomenon of customers' desired value change in a business-to-business context. Journal of Marketing, 66(4): 102-117.

Foss, N. J. 2011. Invited editorial: Why micro-foundations for resource-based theory are needed and what they may look like. Journal of Management, 37(5): 1413-1428.

Gebhardt, G. F., Carpenter, G. S., \& Sherry Jr, J. F. 2006. Creating a market orientation: A longitudinal, multifirm, grounded analysis of cultural transformation. Journal of Marketing, 70(4): 37-55.

Gephart, R. P. 2004. Qualitative research and the Academy of Management Journal. Academy of Management Journal, 47(4): 462-545.

Gereffi, G., Humphrey, J., \& Sturgeon, T. 2005. The governance of global value chains. Review of International Political Economy, 12(1): 78-104.

Gergin, K. 1982. Toward transformation in social knowledge. New York: Springer-Verlag.

Glaser, B. G. 1978. Theoretical sensitivity: Advances in the methodology of grounded theory. Mill Valley, CA: Sociology Press. 
Glaser, B. G. 1992. Emergence vs forcing: Basics of grounded theory analysis. Mill Valley, CA: Sociology Press.

Glaser, B. G. 1999. Keynote address for the fourth annual qualitative health research conference. Paper presented at Qualitative Health Research.

Glaser, B. G. 2001. The grounded theory perspective: Conceptualization contrasted with description. Mill Valley, CA: Sociology Press.

Glaser, B. G. 2002. Constructivist grounded theory? Paper presented at Forum Qualitative Sozialforschung/Forum: Qualitative Social Research.

Glaser, B. G. 2008. Doing quantitative grounded theory. Mill Valley, CA: Sociology Press.

Glaser, B. G., \& Strauss, A. L. 1967. The discovery of gounded theory. Chicago: Aldine.

Glaser, B. G., \& Strauss, A. L. 2009. The discovery of grounded theory: Strategies for qualitative research. Piscataway, NJ: Transaction Publishers.

Gligor, D. M., \& Holcomb, M. 2013. The role of personal relationships in supply chains: An exploration of buyers and suppliers of logistics services. International Journal of Logistics Management, 24(3): 328-355.

Goulding, C. 1998. Grounded theory: The missing methodology on the interpreivist agenda. Qualitative Marketing Research: An International Journal, 1(1): 50-57.

Goulding, C. 2002. Grounded theory: A practical guide for management, business and market researchers. Thousand Oaks, CA: Sage.

Griffith, D. A., Cavusgil, S. T., \& Xu, S. 2008. Emerging themes in international business research. Journal of International Business Studies, 39(7): 1220-1235.

Grosse, R., \& Behrman, J. N. 1992. Theory in international business. Transnational Corporations, 1(1): 93-126. 
Gupta, R., Banerjee, P., \& Gaur, J. 2012. Exploring the role of the spouse in expatriate failure: A grounded theory-based investigation of expatriate'spouse adjustment issues from India. International Journal of Human Resource Management, 23(17): 3559-3577.

Hamel, G. 1991. Competition for competence and interpartner learning within international strategic alliances. Strategic Management Journal, 12(S1): 83-103.

Heath, H., \& Cowley, S. 2004. Developing a grounded theory approach: A comparison of glaser and strauss. International Journal of Nursing Studies, 41(2): 141-150.

Hendrick, C., \& Johns, E. E. 1972. Formal aspects of theory and hypothesis testing. In C. Hendrick \& R. A. Jones (Eds), The nature of theory and research in social psychology: 3-25. New York: Academic Press.

Kim, S. K., Stump, R. L., \& Oh, C. 2009. Driving forces of coordination costs in distributorsupplier relationships: Toward a middle-range theory. Journal of the Academy of Marketing Science, 37(4): 384-399.

Kotabe, M., Parente, R., \& Murray, J. Y. 2007. Antecedents and outcomes of modular production in the brazilian automobile industry: A grounded theory approach. Journal of International Business Studies, 38(1): 84-106.

Lanctot, A., \& Swan, K. S. 2000. Technology acquisition strategy in an internationally competitive environment. Journal of International Management, 6(3): 187-215.

Locke, K. 2015. Pragmatic reflections on a conversation about grounded theory in management and organization studies. Organizational Research Methods, 18(4): 612619.

MacInnis, D. J. 2011. A framework for conceptual contributions in marketing. Journal of Marketing, 75(4): 136-154. 
Maznevski, M. L., \& Chudoba, K. M. 2000. Bridging space over time: Global virtual team dynamics and effectiveness. Organization Science, 11(5): 473-492.

Mello, J., \& Flint, D. J. 2009. A refined view of grounded theory and its application to logistics research. Journal of Business Logistics, 30(1): 107-125.

Morck, R., \& Yeung, B. 2007. History in perspective: Comment on Khanna "Bringing history (back) into international business”. Journal of International Business Studies, 38(2): 357-360.

Morris, M. W., Williams, K. Y., Leung, K., Larrick, R., Mendoza, M. T., Bhatnagar, D., Li, J., Kondo, M., Luo, J.L., \& Hu, J.-C. 1998. Conflict management style: Accounting for cross-national differences. Journal of International Business Studies, 29(4): 729-747.

Morris, S., Hammond, R., \& Snell, S. 2014. A microfoundations approach to transnational capabilities: The role of knowledge search in an ever-changing world. Journal of International Business Studies, 45(4): 405-427.

Nachum, L., \& Keeble, D. 2001. External networks and geographic clustering as sources of MNE advantages: Foreign and indigenous professional service firms in Central London. Cambridge: ESRC Centre for Business Research, University of Cambridge.

O’Reilly, K., Paper, D., \& Marx, S. 2012. Demystifying grounded theory for business research. Organizational Research Methods, 15(2): 247-262.

O'Connor, M. K., Netting, F. E., \& Thomas, M. L. 2008. Grounded theory managing the challenge for those facing institutional review board oversight. Qualitative Inquiry, 14(1): $28-45$.

Palka, W., Pousttchi, K., \& Wiedemann, D. G. 2009. Mobile word-of-mouth - A grounded theory of mobile viral marketing. Journal of Information Technology, 24(2): 172-185. 
Paroutis, S., \& Heracleous, L. 2013. Discourse revisited: Dimensions and employment of first-order strategy discourse during institutional adoption. Strategic Management Journal, 34(8): 935-956.

Pratt, M. G., Rockmann, K. W., \& Kaufmann, J. B. 2006. Constructing professional identity: The role of work and identity learning cycles in the customization of identity among medical residents. Academy of Management Journal, 49(2): 235-262.

Quinn, J. B. 1999. Strategic outsourcing: leveraging knowledge capabilities. Sloan Management Review, 40(4): 9-21.

Ravasi, D., \& Schultz, M. 2006. Responding to organizational identity threats: Exploring the role of organizational culture. Academy of Management Journal, 49(3): 433-458.

Robrecht, L. C. 1995. Grounded theory: Evolving methods. Qualitative Health Research, 5(2): 169-177.

Roth, K., \& Kostova, T. 2003. The use of the multinational corporation as a research context. Journal of management, 29(6): 883-902.

Shenkar, O. 2004. One more time: International business in a global economy. Journal of International Business Studies, 35(2): 161-171.

Simpson, D., Meredith, J., Boyer, K., Dilts, D., Ellram, L. M., \& Leong, G. K. 2015. Professional, research, and publishing trends in operations and supply chain management. Journal of Supply Chain Management, 51(3): 87-100.

Sousa, C. A., \& Hendriks, P. H. 2006. The diving bell and the butterfly the need for grounded theory in developing a knowledge-based view of organizations. Organizational Research Methods, 9(3): 315-338.

Strauss, A. L., \& Corbin, J. M. 1990. Basics of qualitative research: Grounded theory procedures and techniques. Newbury Park, CA: Sage. 
Strauss, A. L., \& Corbin, J. M. 1998. Basics of qualitative research: Techniques and procedures for developing grounded theory (2nd edn). Thousand Oaks, CA: Sage.

Strauss, A. L. 1987. Qualitative analysis for social scientists. Cambridge: Cambridge University Press.

Strong, C. 2015. Humanizing big data: Marketing at the meeting of data, social science and consumer insight. London: Kogan Page Publishers.

Suddaby, R. 2006. What ground theory is not. Academy of Management Journal, 49(4): 633642.

Teece, D. J. 2014. A dynamic capabilities-based entrepreneurial theory of the multinational enterprise. Journal of International Business Studies, 45(1): 8-37.

Thomas, D. C., Cuervo-Cazurra, A., \& Brannen, M. Y. 2011. From the editors: Explaining theoretical relationships in international business research: Focusing on the arrows, not the boxes. Journal of International Business Studies, 42(9): 1073-1078.

Volkoff, O., Strong, D. M., \& Elmes, M. B. 2007. Technological embeddedness and organizational change. Organization Science, 18(5): 832-848.

Walsh, I., Holton, J. A., Bailyn, L., Fernandez, W., Levina, N., \& Glaser, B. 2015. What grounded theory is ... a critically reflective conversation among scholars. Organizational Research Methods, 18(4): 581-599.

Welch, C., \& Piekkari, R. 2006. Crossing language boundaries: Qualitative interviewing in international business. Management International Review, 46(4): 417-437.

Westney, D. E. 1993. Institutionalization theory and the multinational corporation. In S.

Ghoshal \& D. E. Westney (Eds), Organization theory and the multinational corporation. London: Macmillan Press.

Whetten, D. A. 1989. What constitutes a theoretical contribution? Academy of Management Review, 14(4): 490-495. 
Woodruff, R. B. 1997. Customer value: The next source for competitive advantage. Journal of the Academy of Marketing Science, 25(2): 139-153.

Woodside, A. G. 2014. Embrace• perform• model: Complexity theory, contrarian case analysis, and multiple realities. Journal of Business Research,67(12): 2495-2503.

Wright, M., Filatotchev, I., Hoskisson, R. E., \& Peng, M. W. 2005. Strategy research in emerging economies: Challenging the conventional wisdom. Journal of Management Studies, 42(1): 1-33.

Wu, P. L., Yeh, S. S., \& Woodside, A. G. 2014. Applying complexity theory to deepen service dominant logic: Configural analysis of customer experience-and-outcome assessments of professional services for personal transformations. Journal of Business Research, 67(8): 1647-1670.

Yeung, H. W. 1995. Qualitative personal interviews in international business research: Some lessons from a study of hong kong transnational corporations. International Business Review, 4(3): 313-339.

Zahra, S. A. 2007. Contextualizing theory building in entrepreneurship research. Journal of Business Venturing, 22(3): 443-452.

Zhang, Y., Farh, J.-L., \& Wang, H. 2012. Organizational antecedents of employee perceived organizational support in china: A grounded investigation. International Journal of Human Resource Management, 23(2): 422-446. 
Dr. David M. Gligor is an Assistant Professor of Marketing at University of Mississippi. He holds a PhD in Supply Chain Management from University of Tennessee. His research interests include supply chain agility and supply chain strategy. Dr. Gligor has published in journals such as Journal of Operations Management, Decision Sciences, Journal of Business Logistics, and Journal of Supply Chain Management.

Dr. Carol Esmark is an Assistant Professor of Marketing at Mississippi State University. She is a PhD graduate from the University of Tennessee in Knoxville. Her research interests include retailing, international marketing, loyalty programs, and physical privacy. She has recent publications in the Journal of Operations Management and the Journal of Business Research.

Dr. Ismail Gölgeci is a Lecturer in International Marketing at Norwich Business School, University of East Anglia in Norwich, UK. His academic interests are in international marketing strategy, global value chain management, agility, resilience and innovation. 